
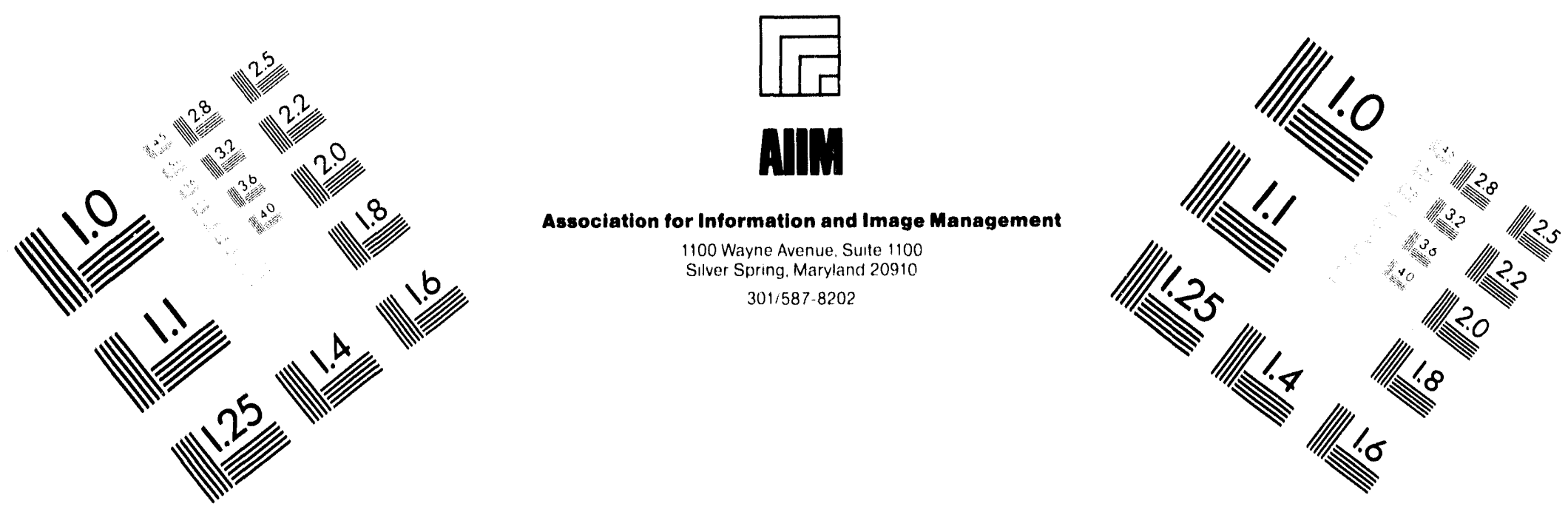

\title{
Centimeter
}

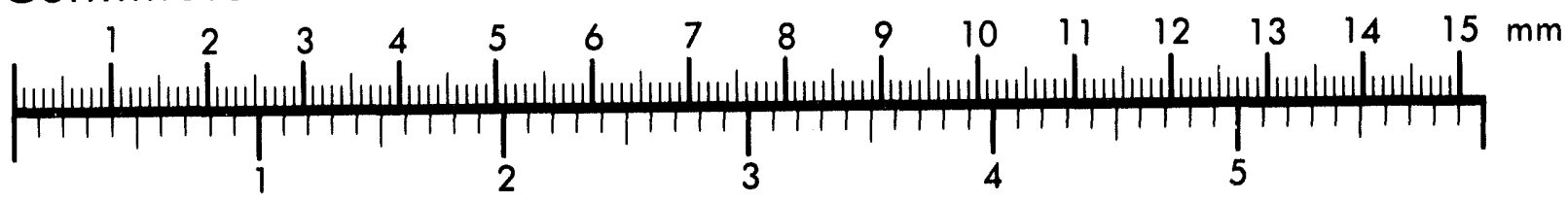

Inches
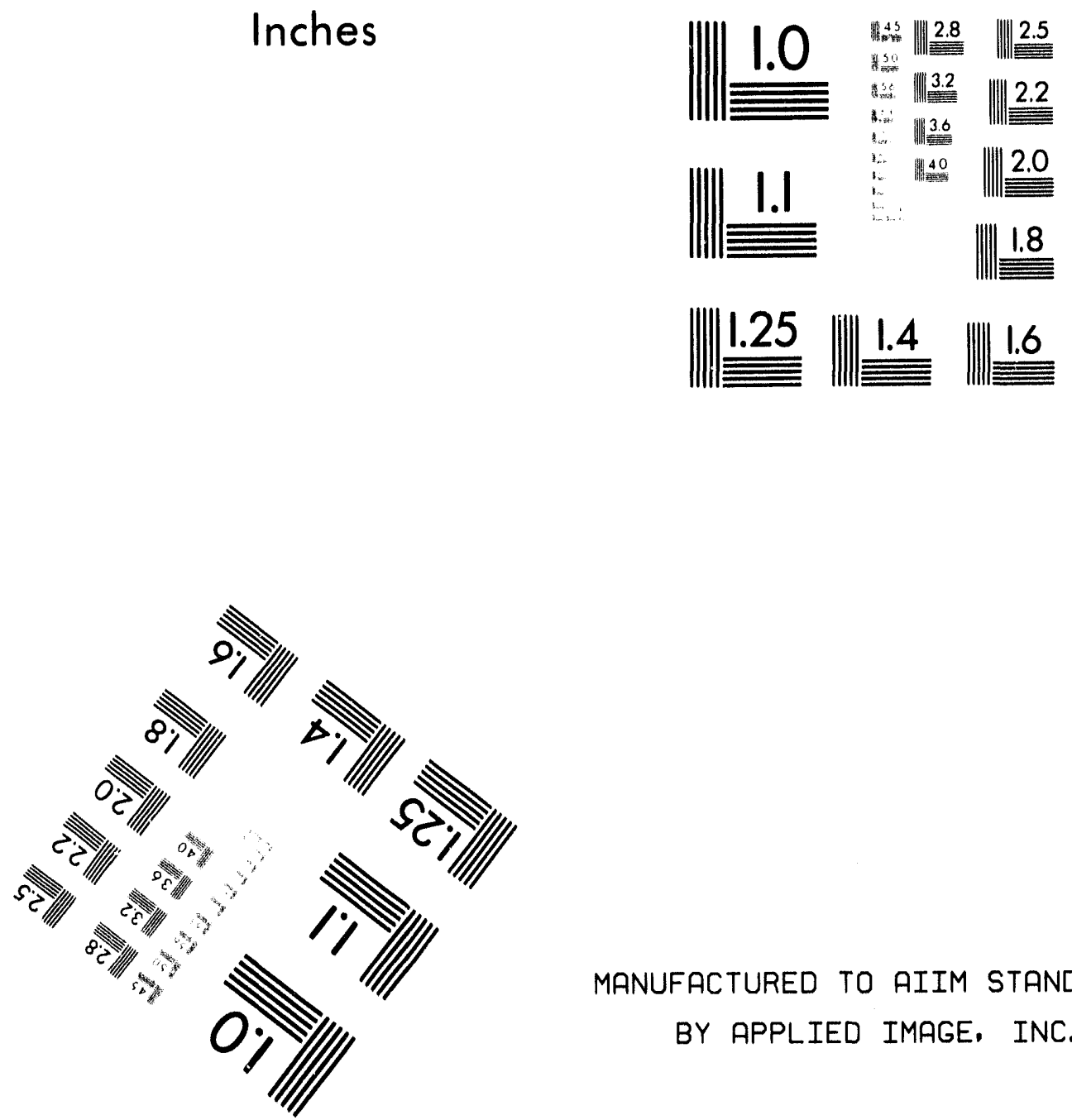

MANUFACTURED TO AIIM STANDARDS

BY APPLIED IMAGE, INC.

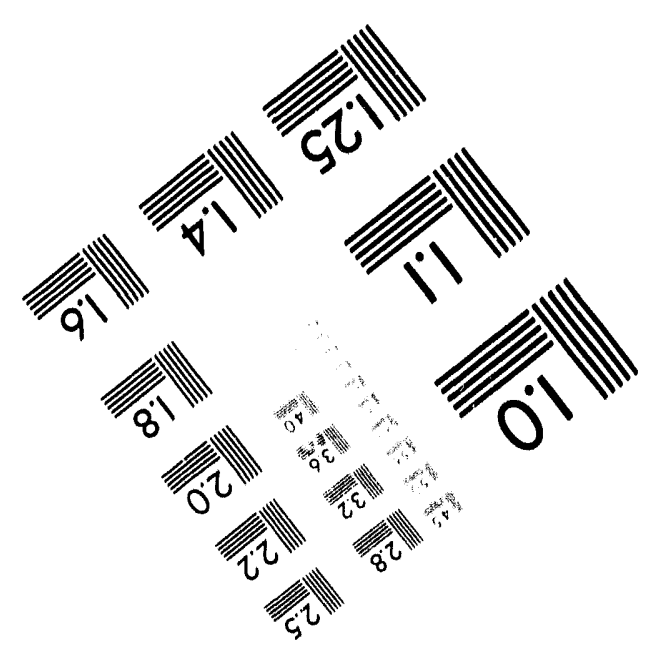


. 


\title{
LA-UR-93- 3234 \\ N-6-93-R140
}

\section{TITLE: POOL BOILING ON THIN HEATERS: THE ROLE OF THERMAL INTERACTION AMONG VAPOR STEMS}

\author{
AUTHOR(S): Pratap Sadasivan \\ Cetin Unal \\ Ralph A. Nelson
}

\author{
SUBMITTED TO: 10th International Heat Transfer Conference \\ August 1994 \\ Brighton, England
}

DISCLAIMER

\begin{abstract}
This report was prepared as an account of work sponsored by an agency of the United States Government. Neither the United States Government nor any agency thereof, nor any of their employees, makes any warranty, express or implied, or assumes any legal liability or responsibility for the accuracy, completeness, or usefulress of any information, apparatus, product, or process disclosed, or represents that its use would not infringe privately owned rights. Reference herein to any specific commercial product, process, or service by trade name, trademark, manufacturer, or otherwise does not necessarily constitute or imply its endorsement, recommendation, or favoring by the United States Government or any agency thereof. The views and opinions of authors expressed herein do not necessarily state or reflect those of the United States Government or any agency thereof.
\end{abstract}

\section{CEIVED \\ OCT 071993 \\ OSTI}

By acceptance of this articte, the publisher recognizes that the U. S. Covernment retalns a nonexclustve, royalty-tree license to publish or reproduce the published form of this contribution, lo allow others to do so, lor U. S. Government purposes.

The Los Alamos National Leboralory requests that the publisher identily this anticle as work pertormed under the ausplces of the U. S. Department of Energy.

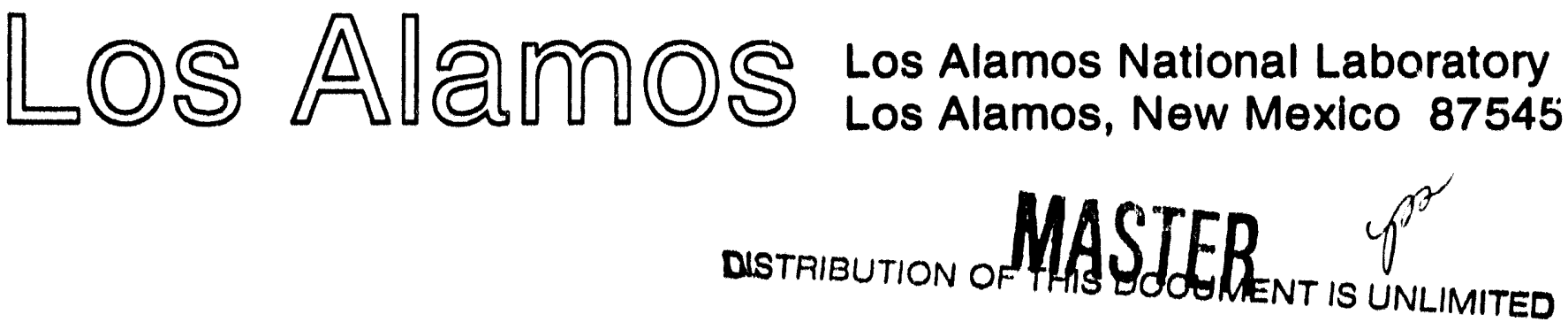




\title{
POOL BOILING ON THIN HEATERS: THE ROLE OF THERMAL INTERACTION AMONG VAPOR STEMS
}

\author{
Pratap Sadasivan, Cetin Unal, and Ralph Nelson
}

\author{
Los Alamos National Laboratory \\ Nuclear Engineering and Technology Division \\ Engineering and Safety Analysis Group \\ Los Alamos, NM 87545
}

\begin{abstract}
We examine the issue of thermal interactions within a heater as a possible explanation for conflicting critical heat flux data on thin heaters, as reported by various investigators. While heater thermal properties have been considered in previous studies, the focus of this study is the interaction between the thermal transport process within the heater and the distribution of nucleation sites on the heater surface. It is shown that the spatial distribution of stems on the heater surface, as well as the size distribution of these stems, can affect the average surface temperatures. Such interactions are greater as the heater thickness decreases.
\end{abstract}

\section{INTRODUCTION}

Previous studies dealing with the critical heat flux (CHF) in pool boiling disagree sharply on the issue of heater thickness effects. In one of the earliest studies dealing with this issue, Carne and Charlesworth (1966) obtained data for isopropanol boiling on flat heaters for a wide range of heater materials and thicknesses. They proposed that the thermal conductance (the product, $k \delta$ ) of the heater can be used as a correlating parameter to describe both effects concurrently.

Houchin and Lienhard (1966) proposed that CHF on thin heaters occurs when the temperature of a dry spot on the heater surface exceeds the Liedenfrost temperature. They used the heater thermal capacitance (the product, $\delta \rho C_{p}$ ) as the correlating parameter for CHF. Tachibana et al. (1967) also used the heater thermal capacitance to correlate the CHF.

Guglielmini and Nannei (1976) used the parameter $\sqrt{\rho C_{p} k}$ to correlate CHF. Carvalho and Bergles (1990) proposed that the heater thickness, $\delta$, by itself can be used to correlate CHF data. Bar-Cohen (1991) proposed that the heater "thermal conpacitance," $\delta \sqrt{\rho C_{p k}}$, is the most suitable correlating parameter. 
Recently, Carvalho and Bergles (1992) assessed the various correlating parameters in terms of their ability to correlate CHF data from a number of sources, including the data sets that were the bases on which each of these parameters was originaly proposed. Their results showed that none of the correlating parameters was able to work consistently well with all data sets. They attempted to rank the various parameters on the basis of their correlative ability with different data sets. They found that $\delta \sqrt{\rho C_{p} k}$, was the best overall correlating parameter. However, the correlative ability was useful only in a very general sense. When considering any individual data set, other correlating parameters could be more effective in correlating the set in question. Carvalho and Bergles (1992) correlated a large set of CHF data in terms of $\delta \sqrt{\rho C_{p k}}$. The resulting equation had a correlation coefficient of less than 0.65 . They attributed this relatively low correlation coefficient to the fact that the original data involved considerable scatter and because the data set included $\mathrm{CHF}$ data from a variety of configurations.

In this paper, we examine the issue of thermal interactions within the heater as a possible explanation for conflicting CHF data on thin heaters as reported by various investigators. While the heater thermal properties have been considered in previous studies, the focus of this study is the interaction between the thermal transport process within the heater and the distribution of nucleation sites on the heater surface. If thermal interactions among nucleation sites affect the process, this finding would support the view that a suitable correlating parameter for high-heat-flux nucleate boiling and CHF on thin heaters must include appropriate representation of the active nucleation site characteristics.

\section{PREVIOUS STUDIES ON INTERACTIONS}

Interactions among nucleation sites in low-heat-flux boiling (discrete bubble region) have been investigated by several researchers. Notable among these are the studies of Judd and coworkers [see, for example, Sultan and Judd (1983), Calka and Judd (1985)].

Recently, other attempts have been made to examine the thermal interactions between sites. Kenning (1990) analytically showed that spatial variations in the temperature as a result of interactions between individual nucleation sites could be of the same order as the surface superheat. Pasamehmetoglu and Nelson (1991) investigated the interaction between individual sites by looking at the conduction problem within the heater numerically. They found that there can be fairly significant nonlinear interaction effects depending on the spatial distribution of the cavities.

These studies have focused on the low-heat-flux nucleate boiling region. The problem becomes more complicated when one has to deal with interactions in the high-heat-flux boiling regime. The vapor removal process no longer is in the form of discrete bubbles. Instead, the high-heat-flux region is characterized by the existence of a liquid macrolayer on the heater surface. The macrolayer is 
interspersed with numerous vapor stems. The precise mechanism of formation of the vapor stems is unclear. Previous studies [Pasamehmetoglu et al. (1993)] have shown that the major component of heat dissipation in the high-heat-flux nucleate boiling regime is the heat transfer that occurs at the base of the vapor stems. This finding contradicts the results of other less realistic heat transfer models that incorporate transient transport into the macrolayer as the main component of heat dissipation. The efficacy of the base of the vapor stems in heat dissipation is supported by several studies. At the base of the vapor stems, three phases are in contact. This triple-interphase contact line is characterized by a meniscus. Wayner and coworkers [for example, Wayner and Coccio (1971) and Renk and Wayner (1979)] have extensively studied the heat transfer associated with the meniscus. Their results indicate that an extremely small portion of the meniscus (the evaporating thin-film region) can act as a very efficient localized heat sink.

The important role of the vapor stem menisci in the high-heat-flux nucleate boiling process suggests that thermal interactions could be important. Experiments have confirmed that the vapor void fraction in the macrolayer is relatively low. Thus, the spatial distribution of the vapor stems within the macrolayer could be significantly different from one experiment to another. If the formation of vapor stems is related to the coalescence of neighboring bubbles, the distribution of the vapor stems on the surface is related to the distribution of active nucleation sites. If the base of a vapor stem is associated with a highly efficient heat sink, the formation of a stem at one location will act to lower the surface temperature in the immediate vicinity of that point. If the temperature of neighboring nucleation sites is lowered sufficiently, they will not activate the next time fresh liquid is supplied to the surface.

Several studies of CHF on thin heaters [e.g., Houchin and Lienhard (1966)] have established the importance of the formation and growth of dry areas on the heater surface. If the heater surface temperature distribution is affected by thermal interactions among vapor stems, this interaction can affect dry patch formation and in turn affect the high-heat-flux boiling curve and CHF. Verification of such thermal interactions by experimental means is an extremely formidable task because the lengths and time scales involved are extremely small. In the present study, we will examine this issue by numerical means. The objective is more to obtain a qualitative sense of the possible role of thermal interactions than to obtain quantitative results. With considerable uncertainty in various aspects of the phenomenon, quantitative results by themselves would lack substantive meaning.

\section{HEAT TRANSFER MODEL}

The physical model of high-flux-boiling proposed by Pasamehmetoglu et al. (1993) is used in the present analysis. The high-heat-flux nucleate boiling process is analyzed by solving the three-dimensional transient conduction problem in the combined macrolayer-heater domain. An analysis code, MACRO3D, is used for 
this purpose. A brief description of the method is provided below; details are omitted here for purposes of brevity. The reader is referred to Sadasivan et al. (1993) for more details.

MACRO3D is a lumped-parameter, finite-volume heat conduction code. Boundary conditions are represented as additional heat source terms in the energy balance equations for control volumes subjected to the boundary conditions. A uniform heat flux can be imposed on the heater bottom surface. For thin heaters, this can be changed to internal volumetric heat generatic i to be consistent with common experimental methods. During a hovering period of the vapor mushroom, the macrolayer thickness decreases steadily as a result of evaporation. The macrolayer cannot be replenished during the course of the hovering period. Heat is dissipated from the heater by transient transport into the macrolayer (which is then consumed in evaporation on the top surface of the macrolayer and along the walls of the vapor stems) and by direct evaporation of the meniscus.

We noted earlier that the model of Pasamehmetoglu et al. (1993) showed that the dominant component of heat dissipation in high-heat-flux boiling is the heat transfer associated with the base of the vapor stems. In this region heat transfer occurs primarily as a result of evaporation of the meniscus. Meniscus evaporation is an extremely complex process-it involves the adsorption characteristics of the heater-liquid system and possibly the enhanced thermal conductivity effects postulated by Pan and Lin (1989). Adsorption effects bring contact angle effects into play, as well. No realistic physical modeling of this region has yet been reported in the literature. Pasamehmetoglu et al. (1993) lumped all these effects by means of a "triple-point coefficient," $m_{e}$. As the liquid-solid contact angle increases, the value of the lumped coefficient, $\mathrm{m}_{\mathrm{e}}$, can be expected to decrease. The value of this coefficient was obtained by trial and error such that the calculated surface- and time-averaged (STA) temperature at a given value of heat flux matched the experimentally reported value. Using the experimental data of Katto and Yokoya (1976) for water (at a heat flux of $1.075 \mathrm{MW} / \mathrm{m}^{2}$, heater surface temperature is $389.5 \mathrm{~K}$ ), we obtained a value of $\mathrm{m}_{\mathrm{e}}=75 \times 10^{-6} \mathrm{~kg} / \mathrm{m} \mathrm{s}^{\circ} \mathrm{C}$.

The use of a lumped coefficient to represent the meniscus heat transfer may appear to be an oversimplification. The use of the model of Pasamehmetoglu et al. (1993) as a fully predictive tool in high-heat-flux boiling would be possible only after the inclusion of a more realistic physical model for meniscus heat transfer. However, in the present study the objective is to examine parametric effects on the boiling curve, and therefore the use of $m_{e}$ is reasonable.

Calculations are started with a reasonable but arbitrary initial temperature distribution in the heater. Area- and period-averaged heater surface temperature and heat flux are determined at the end of each hovering period. The macrolayer is replenished with fresh saturated liquid at the end of each period. Calculations are made for successive hovering periods until the area- and period-averaged temperature and heat flux for one period are within a tolerance level of those in the preceding period. 


\section{THE "AVERAGE-STEM" APPROACH}

In anallyzing the macrolayer-controlled heat transfer regime, previous studies have assumed a uniform spatial distribution of stems in the macrolayer. Size variations are neglected as well. Pasamehmetoglu et al. (1993) used a single "average" stem in their calculations. Dhir and Liaw (1989) used a square grid array of stems with equal sizes. As we noted earlier, the distribution and size of the vapor stems are related to those of the active nucleation sites on the surface.

Pasamehmetoglu et al. (1993) obtained the average-stem configuration for the data of Gaertner (1965) in the following manner. Gaertner had measured the number of nucleation sites and correlated the nucleation site density $N / A_{W}$ (in sites $\left./ \mathrm{m}^{2}\right)$ in terms of the heat flux $\left(\mathrm{W} / \mathrm{m}^{2}\right)$ as

$$
q=117.1\left(N / A_{W}\right)^{2 / 3} .
$$

Bhat et al. (1986) proposed the following equation for the wall void fraction $A_{v} / A_{w}$ :

$$
A_{v} / A_{w}=6.206 \times 10^{-4} q^{1 / 4} .
$$

If all vapor stems have the same size, then

$$
A_{v} / A_{W}=\pi R_{s}{ }^{2}\left(N / A_{W}\right) .
$$

At a given heat flux $q, N / A_{W}$ can be determined from Eq. (1) and $A_{v} / A_{W}$ from Eq. (2). The "average" stem radius can then be determined using Eq. (3). The heater area corresponding to the average stem can then be determined from

$$
A_{v} / A_{W}=\pi R_{s}^{2} / A_{h} .
$$

Calculations using the above equations yield a wall void fraction of 2 percent and a nucleation site density of 88 sites $/ \mathrm{cm}^{2}$ at a heat flux of $1.075 \mathrm{MW} / \mathrm{m}^{2}$. Under these conditions, the radius of the average stem is $0.085 \mathrm{~mm}$, and the corresponding heater area is $1.112 \mathrm{~mm}^{2}$. Thus the simplest unit cell corresponding to Gaertner's heater (area $=2025 \mathrm{~mm}^{2}$ ) at a heat flux of $1.075 \mathrm{MW} / \mathrm{m}^{2}$ is a heater of area $1.112 \mathrm{~mm}^{2}$, with one stem of radius $0.085 \mathrm{~mm}$ at its center. As noted earlier, this configuration corresponds to the case where all stems are assumed to have the same size and are spaced uniformly on the heater surface. 


\section{EFFECT OF SPATIAL DISTRIBUTION OF STEMS}

For purposes of examining the influence of spatial distribution of the stems, we carried out the calculations for a domain containing four stems of equal size (four contiguous unit cells). For the moment, we will not consider the issue of activation of sites to form the stems; we assume that four sites are available on the surface under consideration and that all are active at all times. The total area of the problem domain is $4.448 \mathrm{~mm}^{2}$. The simpiest case is shown in Fig. 1a, where the stems are uniformly distributed on a square grid such that the interstem spacing is 6.2 times the diameter of the stems. Water is the boiling liquid. For this case, using a value of $m_{e}=75 \times 10^{-6} \mathrm{~kg} / \mathrm{m} \mathrm{s}{ }^{\circ} \mathrm{C}$, the STA temperature for a $1-\mathrm{mm}$-thick ${ }^{1}$ copper heater is found to be equal to the experimentally measured value of $389.5 \mathrm{~K}$.

In Fig. 1b, there is a small deviation from a uniform distribution. The interstem spacing is twice the stem diameter in one direction; the spacing in the other direction is the same as in the case of the uniform distribution of Fig. 1a. In Fig. 1c, the stems are clustered in one corner of the problem domain; the spacing in both directions is the same and is equal to twice the diameter. Gaertner (1963) claimed that the active nucleation sites are randomly distributed, just as the nucleation sites are. He suggested that clustering of active sites does not occur. Sultan and Judd (1983) showed by experimental means that clustering of active sites does occur. They showed that the bubble flux density was nonuniformly distributed over the heater surface although the nucleation sites themselves were randomly distributed. This suggests that clustering of active sites can indeed occur. Since the formation of vapor stems is related to the behavior of bubbles, clustering of active sites in the discrete bubble regime can lead to clustering of vapor stems in the high-heat-flux region.

In all the calculations reported here, the heat flux was set to $1.075 \mathrm{MW} / \mathrm{m}^{2}$. This value is less than the value of CHF. We have carried out the calculations for this lower heat flux and then made qualitative extensions to the CHF value. Calculations were made for heater thicknesses of $1.0 \mathrm{~mm}, 0.1 \mathrm{~mm}$, and $0.05 \mathrm{~mm}$. For heater thickness of $1.0 \mathrm{~mm}$, a uniform heat flux boundary condition was used on the bottom surface of the heater. For the thinner heaters, internal heat generation was used. Our calculations have shown that changing the mode of heating does not affect the surface temperature distributions. The STA heater surface temperature under stationary conditions were used as a basis for comparing the results of different calculations.

The first set of calculations was made for a copper heater. The results are shown in Fig. 2. For heater thickness of $1 \mathrm{~mm}$, deviations from uniformity in the spatial distribution of vapor stems appear to have only a minimal effect on the STA temperature. This finding suggests that the effect of thermal interactions on the boiling curve can be neglected for thick heaters. However, as shown in Fig. 2, the STA surface temperature is affected significantly by the spatial distribution of

${ }^{1}$ Calculations have shown that the heater surface temperature is independent of thickness for thicknesses over $1.0 \mathrm{~mm}$ when copper heaters are used. 
the stems for heater thicknesses of $0.1 \mathrm{~mm}$ and $0.05 \mathrm{~mm}$. For a heater of thickness $0.0 \mathrm{~mm}$, for example, the STA temperature is $393.8 \mathrm{~K}$ when the stems are uniformly distributed (configuration of Fig. 1a) and $414.9 \mathrm{~K}$ when the stems are clustered as in Fig. 1c. The influence of nonuniformities in the stem distribution is higher as the thickness decreases.

The surface temperature distribution is altered significantly by changes in the spatial distribution of the vapor stems. This fact has further implications for whether additional sites located elsewhere on the surface can be activated. As an example, consider the case of a heater of thickness $0.1 \mathrm{~mm}$, with the initial stem configuration of Fig. 1c. The void fraction for this case is 2 percent, and the STA temperature is $404.4 \mathrm{~K}$. As a result of the clustering of the vapor stems in one corner of the surface, the temperature on the far corner is considerably higher than the STA value. A previously inactive stem site located in this region may now activate if the local superheat is sufficient to initiate nucleation at this site. We will return to this issue later.

Additional calculations were made to investigate the combined effect of stem spatial distribution and nucleation site density on the extent of thermal interactions among the stems. We have already seen the results of calculations for the configurations of Figs. $1 \mathrm{a}, 1 \mathrm{~b}$, and $1 \mathrm{c}$ for N/A $=88$ sites $/ \mathrm{cm}^{2}$. Here, calculations were carried out for two additional values of N/A-22 and 352 sites $/ \mathrm{cm}^{2}$. The void fraction is kept unchanged at 2 percent. The results are shown in Fig. 3. It is clear that the thermal interaction effects become more significant as the site density is decreased. Effects of stem spatial distribution are minimal for a thickness of $1 \mathrm{~mm}$ at the higher N/A values. For the smallest value of N/A used, the 1-mm-thick heater shows some effect of the spatial distribution of the stems. This finding further supports the importance of the active site density on the boilling characteristics of thin heaters.

The active site density also depends on the wettability of the liquid on the heater material. The active cavity distribution may or may not change as the wettability decreases (i.e., as the contact angle increases). As the contact angle increases, Bankoff's (1958) criterion for vapor entrapment in cavities can be satisfied by more cavities if more cavities are available on the surface. In this case, the active site density will increase. However, if all available cavities already have nucleated, any further reduction in wettability will not increase the active site density. Reduced wettability decreases the efficiency of meniscus heat transfer. This phenomenon can be represented by decreasing the value of the parameter $m_{e}$.

A series of calculations was made to examine the effect of stem spatial distribution under reduced wettability conditions. The triple-point coefficient was set to $50 \times 10^{-6} \mathrm{~kg} / \mathrm{m} \mathrm{s}^{\circ} \mathrm{C}$ and represents a 33 percent reduction from the value used earlier. As noted in the previous paragraph, the active site density eithex remains the same or increases as a result of the reduced wettability. Calculations were made for $\mathrm{N} / \mathrm{A}=88$ sites $/ \mathrm{cm}^{2}$ (original value) and $\mathrm{N} / \mathrm{A}=352$ sites $/ \mathrm{cm}^{2}$. The results are shown in Fig. 4. The influence of reduction in wettability on the extent of thermal interaction among vapor stems appears to be 
related to that on the active site density. If the active site density is unchanged as the wettability (and therefore, $m_{e}$ ) is reduced, the STA temperatures increase and the effect of stem spatial distribution is higher. However, for the case when the reduction in wettability is accompanied by a four-fold increase in active site density, the STA temperatures decrease and the effect of stem spatial distribution is considerably lower. These results further indicate that boiling characteristics on thin heaters are influenced by the combined effects of active site density, wettability, and spatial distribution of active sites.

Another set of calculations was done to examine the influence of heater thermal conductivity on STA temperatures. These calculations were done for a heater thickness of $0.05 \mathrm{~mm}$. The configurations were kept the same as in Fig. 1-that is, the void fractions and the nucleation site density were kept the same as for copper. The value of the triple-line coefficient was also kept constant at $75 \times 10^{-6} \mathrm{~kg} / \mathrm{m} \mathrm{s}^{\circ} \mathrm{C}$. It should be noted that all these values were based on the experimental data of Gaertner (1965), obtained on a copper heater. As the conductivity of the heater material is reduced, we can expect that the surface temperatures will increase. This increase could result in the activation of additional nucleation sites, which will in turn alter the void fraction and nucleation site density. Therefore, it is questionable whether these values can be applied directly to the case of nickel. The values have been used in the present calculations only for purposes of a parametric study to elucidate the effects of heater transport properties on boiling characteristics.

For a nickel heater of thickness $0.05 \mathrm{~mm}$, the uniform stem distribution case yields a STA surface temperature value of $413.7 \mathrm{~K}$. For the configuration of Fig. $1 b$ (small deviation from uniform dis--ibution), the STA surface temperature is $422.5 \mathrm{~K}$, and for the highly nonuniorm distribution of Fig. 1c, the STA temperature is $440.0 \mathrm{~K}$. The magnitude of the increase in STA temperature with increased deviations from uniformity in stem spatial distribution is comparable to that seen in copper.

\section{EFFECT OF STEM SIZE VARIATIONS}

The use of the average-stem assumption described previously assumes both uniform size and uniform distribution of the stems. In the previous section we have seen that the deviations from uniformity in the spatial distribution can affect the surface temperatures significantly in thin heaters. Now we will examine the effect of deviations from uniformity in the size of the stems.

Boiling experiments typically measure the void fraction at the wall or at some small height above the wall. Indeed, Eq. (2) for the void fraction is an empirical equation obtained using Gaertner's void fraction data. In the averagestem approach described earlier, Eq. (3) was used to relate the heater surface void fraction to the density of active nucleation sites on the heater surface. The assumption here is that all stems (assumed to be circular) have the same radius. If the stems are formed as a result of the formation of bubbles from nucleation 
sites, it is possible that the stem sizes can vary from one stem to the next. Clearly, the same void fraction can be measured for different combinations of stem sizes.

We carried out a set of simple calculations in which small variations in the stem sizes were permitted. The spatial distribution was kept uniform for this set of calculations in a configuration corresponding to Fig. 1a (that is, the center-tocenter distance between the stems was kept uniform). The void fraction was the same as for the previous cases, 2.0 percent. The problem domain in this case is also a square of area $4.448 \mathrm{~mm}^{2}$. Stems 1 and 2 in Fig. 1a have a radius $r_{1}$ and, stems 3 and 4 have a radius $r_{2}$. The case of uniform stem size $\left(r_{1} / r_{2}=1\right)$ has been calculated in the previous section; the STA surface temperature was found to be $393.8 \mathrm{~K}$. When the difference in stem sizes is increased such that $r_{1} / r_{2}$ decreases to 0.21 , the STA surface temperature increases to $399.1 \mathrm{~K}$. As the stem size distribution becomes more nonuniform, the STA temperature increases. However, the magnitude of this increase is considerably less than in the case where the stem spatial distribution is altered. For a more extreme case of size variations, the radius of stems 1,2 , and 3 are set to $r_{1}$ and that of stem 4 to $r_{2}$ such that $r_{1} / r_{2}=0.15$. In this case, the STA surface temperature increases to $404.0 \mathrm{~K}$.

The dominant component of hedt dissipation in the heat flux range used in the present calculations is the heat lost as a result of meniscus evaporation. As has been noted earlier, this component is represented using a triple-point coefficient which represents the mass of liquid evaporated per unit time and temperature difference per unit length of the triple interline of the meniscus. Clearly if meniscus evaporation is the dominant component of heat dissipation, the total length of the interline (the sum of the perimeters of the stems) would be important in determining the heater surface temperature. As $r_{1} / r_{2}$ is decreased, keeping the total stem area (wall void fraction) constant, the length of the meniscus interline decreases. This decrease causes the STA surface temperature to increase.

\section{A MORE GENERAL PROBLEM}

In the previous sections we looked at the effects of spatial distribution and variations in stem sizes on the overall average temperatures. In each case, the stems were located in a certain manner and were assumed to be active at all times. We will now look at a problem involving a more realistic configuration allowing for the possibility of stems being active or inactive depending on conditions that prevail at the stem site.

We will consider the case of a small area of the heater surface that contains six nucleation sites. A square region on the heater surface measuring $0.938 \mathrm{~mm}$ on a side is considered; the heater thickness is set to $0.05 \mathrm{~mm}$. With six sites distributed on this surface, the maximum site density possible is 680 sites $/ \mathrm{cm}^{2}$. The actual density at any time depends on the number of sites active at that time. We assume that a vapor stem is formed at a site if that cavity becomes active and that the radius of the stem is ten times that of the corresponding cavity. That is, we assume, in effect, that the heat fluxes are sufficiently high that the triple- 
interphase line at the bubble base is located outside the cavity rather than inside it. The factor of ten used here to determine the size of the corresponding vapor stems is of an order corresponding to values calculated in previous studies [see, for example, Chappidi et al. (1991)]. It is also assumed that the time elapsed between the nucleation at a cavity and the establishment of the triple-interphase contact line outside the cavity is negligible. These again, are reasonable assumptions in keeping with the heat fluxes of interest here because the bubble growth rates can be expected to be high.

Yang and Kim (1988) found that the size distribution of cavities present on a surface fit a Poisson distribution. In the present problem, using any such distribution to determine the size range of the cavities is not feasible owing to the small number of cavities. However, in the range of diameters of interest we can expect the number of cavities of radius $r_{c}$ to increase as $r_{c}$ decreases. The cavities were located randomly on the heater surface and are numbered as shown in Fig. 5. The results of three configurations are discussed in the following paragraphs. The location of the cavities is kept the same in both cases; the sizes of the cavities are varied, as indicated in Table 1 below.

The activation temperature for each cavity is determined using the equation of Han and Griffith (1965). The lower limits of superheat predicted by their equation have been used. The activation temperatures for the radil of $1 \mu, 2 \mu$, $3 \mu, 4 \mu$, and $5 \mu$ are $425.4 \mathrm{~K}, 399.2 \mathrm{~K}, 391.5 \mathrm{~K}, 386.1 \mathrm{~K}$, and $383.5 \mathrm{~K}$, respectively. The meniscus evaporation coefficient is assigned a value of $75 \times 10^{-6} \mathrm{~kg} / \mathrm{m} \mathrm{s}{ }^{\circ} \mathrm{C}$. A volumetric heat generation equivalent to a surface heat flux of $1.075 \mathrm{MW} / \mathrm{m}^{2}$ is uniformly distributed within the heater. The hovering period is set to $50.5 \mathrm{~ms}$, and it is assumed that all sites are replenished with saturated liquid at the same time.

When a cavity is activated and a vapor stem is formed there, the temperature in the immediate vicinity will drop as a result of the local heat sink associated with the triple-interphase meniscus in that region. As a result, the cavity may deactivate. We assume that such deactivation occurs only between hovering periods and not during a period. During a hovering period, the tripleinterphase contact line is located outside the cavity, and the meniscus is unaffected by the temperature at the cavity mouth. However, when fresh liquid covers the cavity at the beginning of the next hovering period, the cavity will not activate immediately if the superheat is below the activation superheat. As suggested by Kenning (1992), the deactivation superheat is less than the corresponding value for activation. Here, we assume that the deactivation superheat is $5^{\circ} \mathrm{C}$ less than the activation superheat.

All cavities are assumed to be inactive at time $=0$, and calculations are allowed to proceed until stationary conditions are reached. Results for the three configurations listed in Table 1 are presented in Table 2. All results cited are under conditions of stationarity.

It is clear from Table 2 that the average surface temperature and the behavior of cavities are influenced strongly by the distribution of cavities on the surface. The transient state of the cavities in each case for two consecutive 
hovering periods is shown in Fig. 6 . In case $A$, the active cavities 6 and 5 are located close to opposite edges of the heater, so the temperature at cavity 4 (located midway between them) is affected almost equally by the heat sinks associated with 6 and 5 . This prevents the temperature at cavity 4 from reaching the activation value. In case B, the active cavities 6 and 3 activate first, but in this case, cavity 3 is located farther from 4 , thereby reducing the effect of the heat sink at 3 on cavity 4 . Thus, the temperature at cavity 4 exceeds the activation value later in the period, and it activates. In case $C$, the cavities with radii of $4 \mu$ and 3 $\mu$ are active throughout the period; however, the smaller cavities do not reach temperatures sufficient to activate them.

The problem considered here is obviously a simplified and arbitrary case. A real surface has a much larger number of cavities than we have considered here. Nevertheless, the results of this simple problem present an example of the manner in which locations and sizes of cavities can interact to influence the process of thermal conduction within the heater and thus affect the surface temperature distribution.

\section{IMPLICATIONS FOR CHF}

The results of the present study show that thermal interactions among vapor stems as a result of nonuniformities in stem sizes and stem spacing can have significant influences on the heater surface temperatures in macrolayercontrolled nucleate boiling.

Several previous studies have shown that the occurrence of $\mathrm{CHF}$ on thin heaters is related to the formation of dry patches on the surface, which get sufficiently hot so that liquid is no longer able to make contact with that area. ${ }^{2}$ This finding suggests that the occurrence of $\mathrm{CHF}$ is related to the temperature distribution on the hedter surface before CHF is reached. Therefore, as the heater surface temperature in the macrolayer-controlled nucleate boiling is increased, conditions favorable for CHF will occur sooner. Thus, for thin heaters, thermal interactions among vapor stems can affect CHF. Such thermal interactions could be further magnified when double-sided heaters are employed, owing to interactions in both the lateral and axial directions. The above considerations suggest that any correlating parameter for $\mathrm{CHF}$ on thin heaters must also include a representation of the size and spatial distribution of vapor stems on the heater surface. More extensive experiments are needed to determine the most appropriate parameter to be used for this purpose.

\footnotetext{
${ }^{2}$ Recent studies by Unal et al. (1992a, 1992b) have shown that a similar mechanism is viable even for thick heaters.
} 


\section{NOMENCLATURE}

\begin{tabular}{|c|c|}
\hline $\mathbf{A}$ & Area $\left(m^{2}\right)$ \\
\hline$A_{h}$ & Area of unit cell $\left(\mathrm{m}^{2}\right)$ \\
\hline$A_{v}$ & Area of vapor $\left(\mathrm{m}^{2}\right)$ \\
\hline$A_{w}$ & $\begin{array}{l}\text { Area of heater }\left(\mathrm{m}^{2}\right) \\
\text { Specific heat }(\mathrm{T} / \mathrm{kg} \mathrm{K})\end{array}$ \\
\hline $\begin{array}{l}C_{p} \\
d_{s}\end{array}$ & $\begin{array}{l}\text { Specinic heat }(\mathrm{kg} \text { K) } \\
\text { Diameter of stem (m) }\end{array}$ \\
\hline k & Thermal conductivity ( $\mathrm{W} / \mathrm{m} \mathrm{K})$ \\
\hline $\begin{array}{l}\mathrm{m}_{\mathbf{e}} \\
\mathrm{N}\end{array}$ & Triple-point coefficient $\left(\mathrm{kg} / \mathrm{m} \mathrm{s}^{\circ} \mathrm{C}\right)$ \\
\hline$q$ & Heat Flux $\left(\mathrm{W} / \mathrm{m}^{2}\right)$ \\
\hline $\mathbf{r}_{\mathrm{c}}$ & Radius of cavity (m) \\
\hline $\mathbf{R}_{\mathbf{s}}$ & Radius of stem (m) \\
\hline STA & Surface- and time-averaged value \\
\hline$\delta$ & Heater thickness $(m)$ \\
\hline$\rho$ & Density $\left(\mathrm{kg} / \mathrm{m}^{3}\right)$ \\
\hline
\end{tabular}

\section{REFERENCES}

Bankoff, S. G., 1958, "Entrapment of Gas in the Spreading of a Liquid Over a Rough Surface," A.I.Ch.E. Journal, vol. 4, pp. 24-26.

Bar-Cohen, A., 1991, "Thermal Management of Electronic Components with Dielectric Liquids," Proceedings of the ASME/ISME Thermal Engineeing Joint Conference, vol. 2, pp. xv-xxxiv.

Bhat, A. M., Saini, J. S., and Prakash, R., 1986, "Role of Macrolayer Evaporation in Pool Boiling at High Heat Flux," Int. I. Hear Mass Transfer vol. 29, pp. 19531961.

Carne, M., and Charlesworth, D. H., 1966, "Thermal Conduction Effects on the Critical Heat Flux in Pool Boiling," Chemical Engr. Prog. Symp. Ser., vol. 62, pp. 24-34.

Carvalho, R. D. M., and Bergles, A. E., 1990, "The Effect of Heater Thermal Properties and Thickness on the Pool Boiling Critical Heat Flux," Proceedings of the 3rd Brazilian Thermal Sciences Meeting, vol. II, pp. 577-582.

Carvalho, R. D. M., and Bergles, A. E., 1992, "The Effects of the Heater Thermal Conductance/Capacitance on the Pool Boiling Critical Heat Flux," Pool and External Flow Boiling, Proceedings of the Engineering Foundation Conference on Pool and External Flow Boiling, Santa Barbara. 
Chappidi, P. R., Unal, C., Pasamehmetoglu, K. O., and Nelson, R. A., 1991, "Development of a Multiple-Vapor-Stem Model for Saturated Pool Nucleate Boiling at High Heat Fluxes on a Horizontal Surface," Los Alamos National Laboratory report LA-UR-91-1939.

Dhir, V. K., and Liaw, S. P., 1989, "Framework for a Unified Model for Nucleate and Transition Pool Boiling," L. Heat Transfer, vol. 111, pp. 739-746.

Gaertner, R. F., 1963, "Distributions of Active Sites in Nucleate Boiling of Liquids," Chem. Engr. Prog. Symp. Ser., vol. 56, pp. 39-48.

Gaertner, R. F., 1965, "Photographic Study of Nucleate Boiling on a Horizontal Surface," ASME Journal of Heat Transfer, vol. 87, pp. 17-29.

Guglielmini, G., and Nannei, E., 1976, "On the Effect of Heating Wall Thickness on Pool Boiling Burnout," Int. I. Heat Mass Transfer, vol. 19, pp. 1073-1075.

Han, C. Y., and Griffith, P., 1965, "Mechanisms of Heat Transfer in Nucleate Boiling, Part I: Bubble initiation, Growth and Departure." Int I Heat Mass Transfer, vol. 8, pp. 887-904.

Houchin, W. R., and Lienhard, J. H., 1966, "Boiling Burnout in Low Thermal Capacity Heaters," ASME Paper 66-WA/HT-40.

Katto, Y., and Yokoya, S., 1976, "Behavior of Vapor Mass in Saturated Nucleate and Transition Boiling," Heat Transfer. Jap. Res., vol. 5, pp. 45-65.

Kenning, D. B. R., 1990, "Wall Temper:tures in Nucleate Boiling: Spatial and Temporal Variations," Broceedings of the 1990 International Heat Transfer Conference, Jerusalem, vol. 6, pp. 33-38.

Kenning, D. B. R., 1992, "Wall Temperature Variations and the Modeling of Bubble Nucleation Sites," Broceedings of the Engineering Foundation Conference on Pool and External Flow Boiling, Santa Barbara, California, pp. 105-109.

Pan, C., and Lin, T. L. , 1989, "Marangoni Flow on Pool Boiling Near Critical Heat Flux," Int. Comm. Heat Mass Transfer, vol. 16, pp. 475-486.

Pasamehmetoglu, K. O., and Nelson, R. A., 1991, "Cavity-to-Cavity Interaction in Nucleate Boiling: The Effect of Heat Conduction Within the Heater," AIChE Symp. Ser., voi. 87, n283, pp. 342-351. (Also available as Los Alamos National Laboratory document LA-UR-91-165).

Pasamehmetoglu, K. O., Chappidi, P. R., Unal, C., and Nelson, R. A., 1993, "Saturated Pool Nucleate Boiling Mechanisms at High Heat Fluxes," to appear in the Int. I. Heat Mass Transfer. 
Renk, F. J., and Wayner, P. C., 1979, "An Evaporating Ethanol Meniscus, Part I: Experimental Studies," Iournal of Heat Transfer, vol. 101, pp. 55-58.

Sadasivan, P. Unal, C., and Nelson. R. A., 1993, "MACRO3D, A ThreeDimensional Finite Volume Computer Code for the Analysis of High Heat Flux Nucleate Boiling," Los Alamos National Laboratory report, LA-UR-93-1835.

Sultan, M., and Judd, R. L., 1978, "Spatial Distribution of Active Sites and Bubble Flux Density," ASME Journal of Heat Transfer, vol. 100, pp. 56-62.

Unal, C., Sadasivan, P., and Nelson, R. A., 1992a, "On the Hot-Spot-Controlled Critical Heat Flux Mechanism in Pool Boiling of Saturated Fluids," Proceedings of the Engineering Foundation Conference on Pool and External Elow Boiling, SantaBarbara. California pp. 193-201.

Unal, C., Vincent, D., and Nelson, R. A., 1992b, "Unifying the Controlling Mechanisms for the Critical Heat Flux and Quenching: The Ability of Liquid to Contact the Hot Surface," ASME Journal of Heat Transfer, vol. 114, pp. 972-982.

Wayner, P. C., and Coccio, C. L., 1971, "Heat and Mass Transfer in the Vicinity of the Triple Interline of a Meniscus," A.I.Ch.E. Journal vol. 17, pp. 569-574.

Yang, S. R., and Kim, R. H., 1988, "A Mathematical Model of Pool Boiling Nucleation Site Density in Terms of Surface Characteristics," Int. _. Heat Mass Transfer, vol. 31, pp. 1127-1135. 
Table I. Cavity sizes and locations as mapped in Fig. 5, for three cases

\begin{tabular}{|c|c|c|c|}
\cline { 2 - 4 } \multicolumn{1}{c|}{} & \multicolumn{3}{c|}{ Cavity radius $(\mu)$} \\
\hline Cavity number & Case A & Case B & Case C \\
\hline 1 & 1 & 1 & 1 \\
2 & 1 & 1 & 1 \\
3 & 2 & 4 & 2 \\
4 & 3 & 3 & 3 \\
5 & 4 & 2 & 2 \\
6 & 5 & 5 & 4 \\
\hline
\end{tabular}

Table II. Results of cases listed in Table I

\begin{tabular}{|c|c|c|c|}
\cline { 2 - 4 } \multicolumn{1}{c|}{} & Case A & Case B & Case C \\
\hline $\begin{array}{c}\text { Cavities active } \\
\text { throughout each } \\
\text { period } \\
\text { Cavities active for } \\
\text { a portion of each } \\
\text { period }\end{array}$ & 6,5 & None & 6,4 \\
$\begin{array}{c}\text { Cavities inactive } \\
\text { throughout _ach } \\
\text { period }\end{array}$ & $1,2,3,4$ & $1,3,4$ & None \\
$\begin{array}{c}\text { Maximum void } \\
\text { fraction (\%) } \\
\text { STA Temperature } \\
\text { (K) }\end{array}$ & 390.8 & 1.65 & $1,2,3,5$ \\
\hline
\end{tabular}




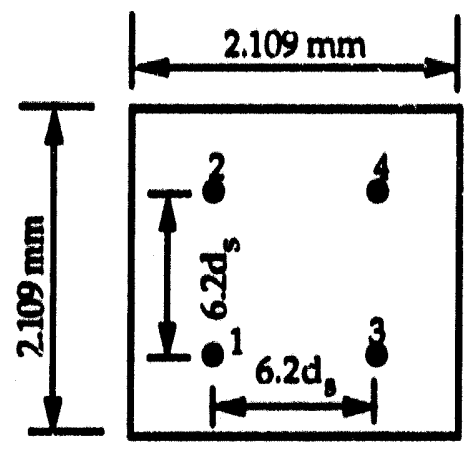

(a) Uniform distribution

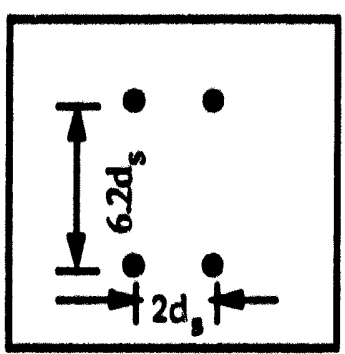

(b) Small deviation from uniformity

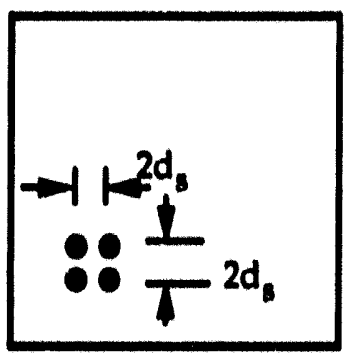

(c) Clustering

Fig. 1. Configurations used to examine influence of spatial distribution of stems $\left(d_{s}=0.17 \mathrm{~mm}\right)$. 


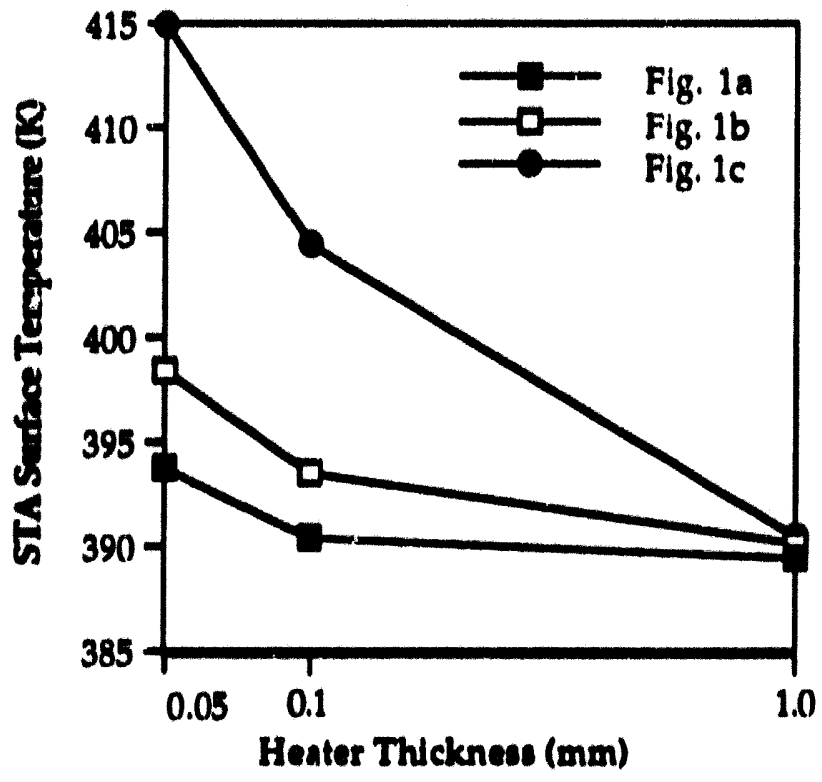

Fig. 2. Effect of stem spatial distribution on surface temperature for copper heaters of different thicknesses.

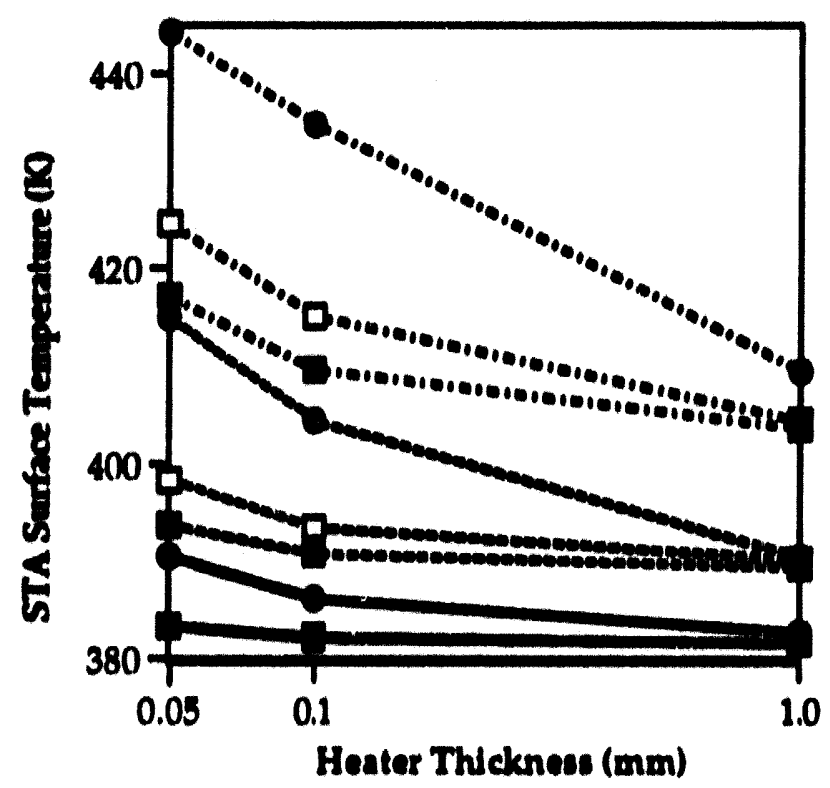

Fig. 3. Effect of stem distribution on STA temperatures for different thicknesses and active site density values

(Solld equares; Fig. 1a; open equares; Fig. Ib; circles; Fig. 1c;

$$
\begin{aligned}
& \text { - } 352 \text { siltes } / \mathrm{cm}^{2} ; \text { - }-88 \text { siten } / \mathrm{cm}^{2} \text {; } \\
& \text { - . - . } 22 \text { alten } / \mathrm{cm}^{2} \text { ). }
\end{aligned}
$$




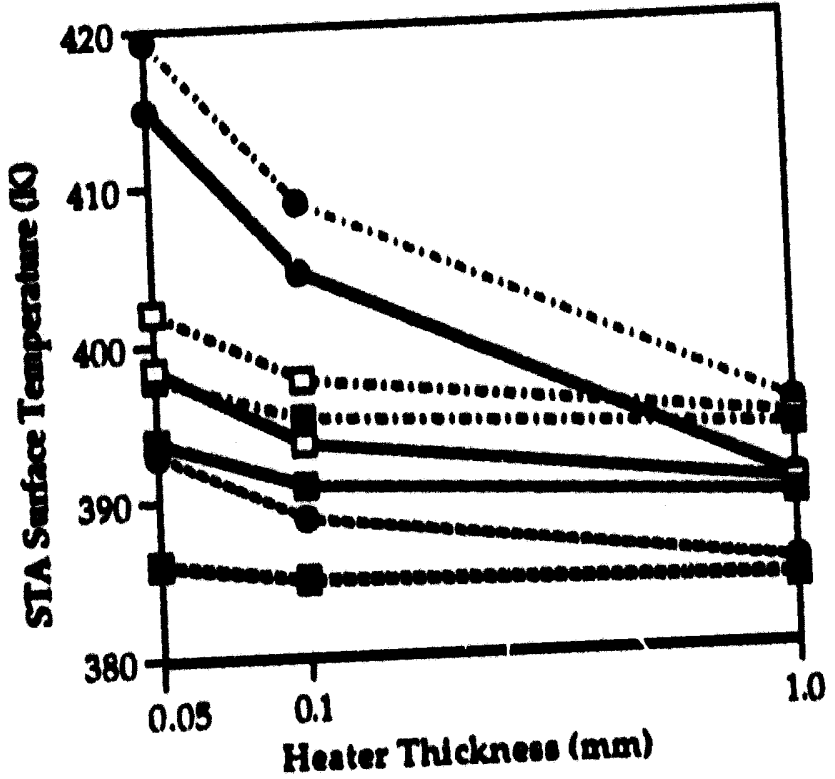

Fig. 4. Effect of wettability on STA temperatures

$$
\begin{aligned}
& \left(-88 \text { sites } / \mathrm{cm}^{2} \text { and } \mathrm{m}_{\mathrm{c}}=75 \times 10^{-6} \mathrm{~kg} / \mathrm{m}{ }^{\circ} \mathrm{C}\right. \text {; } \\
& \text { - - }-88 \text { siten } / \mathrm{cm}^{2} \text { and } m_{e}=50 \times 10^{-6} \mathrm{~kg} / \mathrm{m} /{ }^{\circ} \mathrm{C} \text { ). }
\end{aligned}
$$




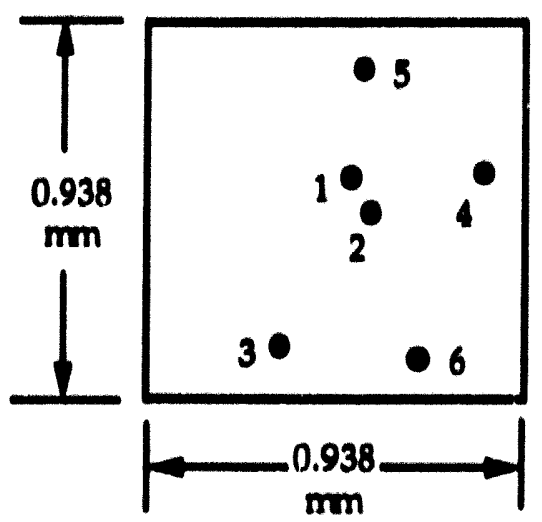

Fig. 5. Map of cavities on heater surface for cases listed in Table I.
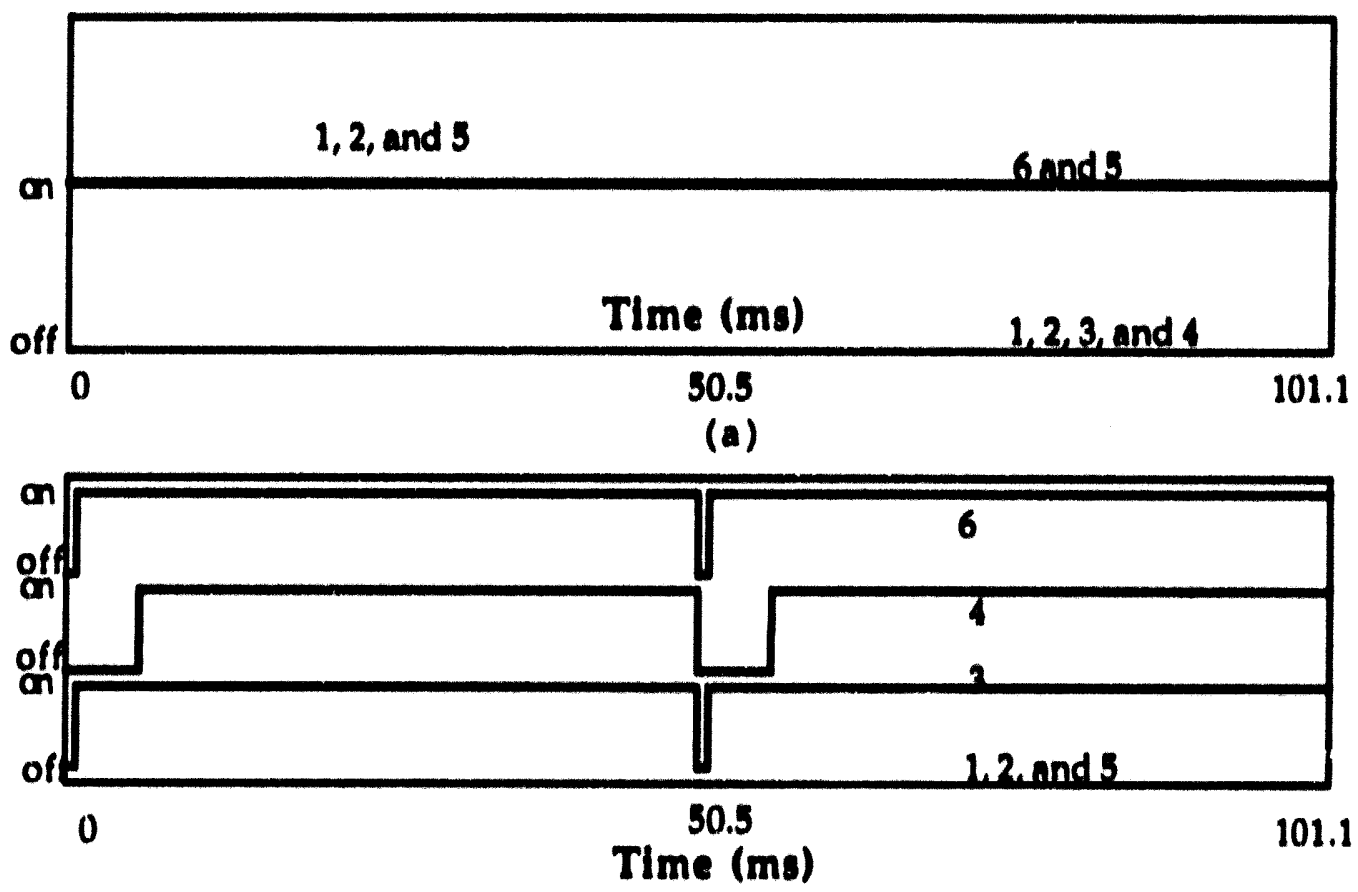

(b)

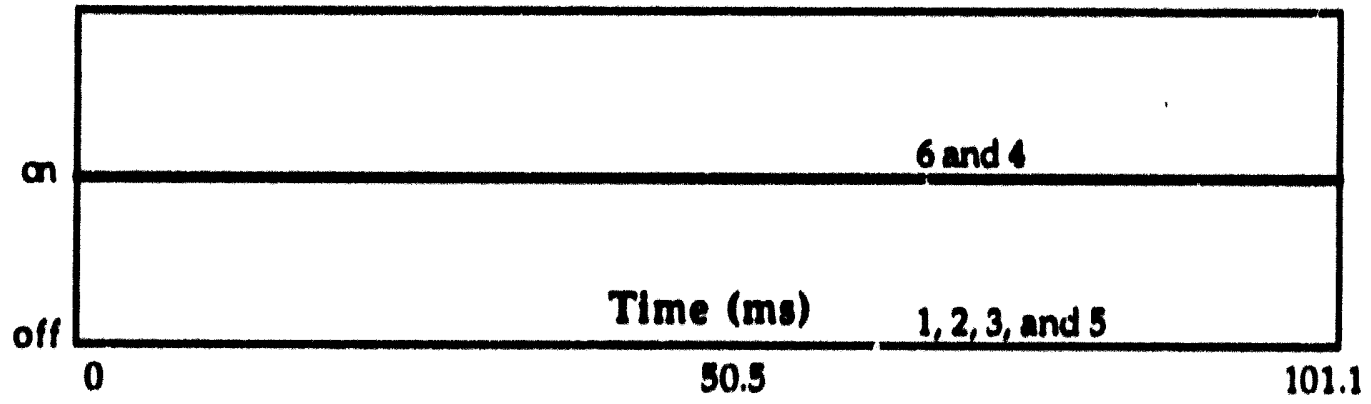

(c)

Fig. 6. Status of stem siles during two consecuttve perlods for configurations of Table l: (a) case A, (b) case B, (c) case C. 
Table I. Cavity sizes and locations as mapped in Fig. 5, for three cases

\begin{tabular}{|c|c|c|c|}
\cline { 2 - 4 } \multicolumn{1}{c|}{} & \multicolumn{3}{|c|}{ Cavity radius $(\mu)$} \\
\hline Cavity number & Case A & Case B & Case C \\
\hline 1 & 1 & 1 & 1 \\
2 & 1 & 1 & 1 \\
3 & 2 & 4 & 2 \\
4 & 3 & 3 & 3 \\
5 & 4 & 2 & 2 \\
6 & 5 & 5 & 4 \\
\hline
\end{tabular}

Table II. Results of cases listed in Table I

\begin{tabular}{|c|c|c|c|}
\hline & Case A & Case B & Case C \\
\hline $\begin{array}{l}\text { Cavities active } \\
\text { throughout each } \\
\text { period }\end{array}$ & 6,5 & None & 6,4 \\
\hline $\begin{array}{l}\text { Cavities active for } \\
\text { a portion of each } \\
\text { period }\end{array}$ & None & $6,3,4$ & None \\
\hline $\begin{array}{l}\text { Cavities inactive } \\
\text { throughout each } \\
\text { period }\end{array}$ & $1,2,3,4$ & $1,2,5$ & $1,2,3,5$ \\
\hline $\begin{array}{l}\text { Maximum void } \\
\text { fraction (\%) }\end{array}$ & 1.35 & 1.65 & 1.25 \\
\hline $\begin{array}{l}\text { STA Temperature } \\
\text { (K) }\end{array}$ & 390.8 & 388.1 & 395.5 \\
\hline
\end{tabular}


